\title{
UNA PINTURA EN TABLA DE LA DUDA DE SANTO TOMÁS DE FRANS FRANCKEN II ATRIBUIDA AL PRIMERO DE LA DINASTÍA
}

\section{A PAINTING ON WOOD OF THE INCREDULITY OF SAINT THOMAS BY FRANS FRANCKEN II ASSIGNED TO FIRST DYNASTY}

\author{
Matías DíAz PADRón \\ Real Academia de Arqueología e \\ Historia del Arte de Bélgica \\ magdala@epi.es
}

\begin{abstract}
En el presente trabajo se sostiene la atribución al pintor flamenco de una tabla con el tema de la incredulidad del citado apóstol de Cristo.

Palabras clave: Pintura barroca flamenca

In this paper attribution to the Flemish painter holds a table with the theme of disbelief apostle of Christ quoted.

Key words: Flemish Baroque painting.
\end{abstract}

Pensamos de interés la publicación de esta pintura de Frans Francken II con la incertidumbre de Santo Tomás por más de una razón (Figura 1) ${ }^{1}$. Fue en Sevilla donde localizamos y publicamos hace años los lienzos de mayor tamaño conocido en España de este pintor, catalogados entonces entre los anónimos de la catedral de Sevilla ${ }^{2}$. Eran las pinturas más ambiciosas del artista a extramuros de Flandes. Añadimos entonces otras inéditas u olvidadas y noticias de una

${ }^{1}$ T. 77 x 102,2 cm en el coleccionismo español

${ }^{2}$ M. Díaz Padrón, "Frans Francken II en la catedral de Sevilla algunas consideraciones a su obra en España", Goya, 1975, n 129, p 168 
importación considerable desde Flandes a través del Cantábrico como a través de los pujantes puertos de Andalucía. La segunda razón está en la atribución incorrecta a Frans Francken I, o Frans Francken el Viejo, sin advertir la técnica y estilo peculiar de Frans Francken II, Frans Francken el joven, el más famoso de la saga $^{3}$.

Las medidas son las propias de la pintura de gabinete. La incorrecta atribución obliga a una especial atención a Frans Francken I. Es pintor de formación estética en el romanismo pujante a fines del XVI y principios del XVII, contemporáneo de Frans Floris, Martin de Vos y Otto Vaenius, distante de lo que transmite la pintura que tratamos. Evidente es su vínculo con Frans Francken II, hijo del primero del nombre y más próximo a la corriente barroca de Rubens en los Países Bajos. Nada hay en común con el tríptico de la catedral de Amberes de Frans Francken I, el Calvario de Dresde y tríptico del Museo de Sevilla ${ }^{4}$, muy distantes a la factura pictórica minuciosa y animada de la Incredulidad de Santo Tomás. Muy lejos de la monumentalidad y factura lisa del pintor romanista.

La Incredulidad de Santo Tomás, ahora en el coleccionismo español, nos permite revisar y rectificar la propuesta de la galería londinense. La firma " $A^{o} D$ FFRANCK IN Fec" corresponde a Frans Francken II. Un pintor fecundo dentro y fuera de su país. Tampoco encontramos referencia alguna a esta obra en el copioso catálogo de Frans Francken II, ni lectura de su contenido.

Jesús ocupa el eje del interior de una estancia en penumbra que sirve de escenario a la historia, enmarcada entre paredes y muros de diseño clásico. Un amplio cortinaje cae del techo junto a un robusto pilar a campo abierto. Allí se desarrolla una escena que conjuga con la historia que está a la vista del espectador: la aparición de Jesús a sus discípulos después de la resurrección y la duda de santo Tomás. Este hunde su mano y sus dedos en la herida del costado que el centurión asestó con su lanza en el Calvario.

Santo Tomás puso siempre en duda la vuelta de Jesús a la vida. El encuentro era la prueba de su resurrección. Este se produce en una estancia con las puertas cerradas. La aparición de Jesús no fue sorpresa para los restantes apóstoles. "-Mete tus manos aquí y mira las mías. Acerca tu mano y métela en mi costado y no seas incrédulo, sino fiel" (Juan 20, 27). Nada mas dice el texto salvo la exclamación: "-¡Señor mío y Dios mío! Y Jesús le dijo- Porque me has visto has creído. Bienaventurados los que sin ver creyeron".

No era un tema frecuente en la iconografía a pesar de hundir sus raíces en mosaicos del siglo X. Esta incredulidad situó a santo Tomás en el segundo rango del apostolado. Aquella duda caló en los dos apóstoles que consultan unos libros

\footnotetext{
${ }^{3}$ Sotheby's Londres, 3 de julio de 1996, no 265

${ }^{4}$ Véase Le Dictionnaire des Peintres Belges du XIVe siècle à nos jours, 1995, p. 450 y J. Bruyn, "Francisco Frutet of Frans I?", Jaarboek van het Koninklijk Museum voor Schone Kunsten, Amberes, 1962-1963, pp. 56 y ss.
} 
a la izquierda de la composición. Aunque frecuentemente Santo Tomás aparece de pie aquí está arrodillado. Es la escena más divulgada de la vida del santo ${ }^{5}$. Rubens había tratado el mismo asunto con Jesús con el busto desnudo, manto rojo en el brazo izquierdo y cabellos largos en el tríptico del museo de Amberes. El nimbo adquiere unas proporciones excesivas en la versión de Frans Francken, quizá por alcanzar la eternidad en el cielo.

El culto del apóstol no estuvo muy extendido en España. Una excepción está en la iglesia de Santo Tomé con El entierro del conde Orgaz de El Greco. Tampoco está divulgado el martirio del santo. Aquí está en una secuencia al fondo y a la derecha de la composición (Figura 2). El rey Gondóforo había solicitado la presencia de un hábil constructor para diseñar su palacio, por lo que su ministro Abanes recomendó a santo Tomás. El palacio debía competir con los de Roma. Esto relata Santiago de la Vorágine ${ }^{6}$.

Pensamos que la evocación del proyecto está en la construcción a lo alto de la montaña. Es una repetición exacta del templo de la Sibila de Tívoli que dibujó, entre otros muchos artistas, Jan Brueghel el Viejo en la fundación Custodia (Figuras 3 y 4). A ras de tierra está el santo arrastrado por sus verdugos. En el interior de una oscura cueva. Había convertido a la fe a muchos en la ausencia del rey. Aquello le costó la vida "lo encerró juntamente con Abanes en un calabozo profundo, mandó que a los dos los desollasen vivos y que arrojasen sus cuerpos a las llamas vengadoras"7. La historia la narra con detalle La Leyenda Dorada.

El interior de la estancia se anima con el color de las túnicas de los apóstoles. Santo Tomás, San Pedro y San Juan son fácilmente identificables a pesar de la incapacidad de Francken para individualizar sus modelos. Todos esperan la prueba de la resurrección salvo los sentados a la derecha de Jesús con gruesos libros recordados líneas atrás. Todo alineado en el primer plano. Recurso que Frans Francken II toma del teatro. La ejecución vibrante y los modelos idealizados son típicos y muy repetidos suyos. Un virtuosismo técnico que alcanza mayor estimación en estos últimos años.

Es conocida la abundancia de obras de Frans Francken en España ${ }^{8}$. La buena conservación se debe a su gran calidad. El encanto y gracia de Frans Francken II hace que su obra revierta en la pintura de género a pesar del drama representado.

${ }^{5}$ RÉAU, Louis: Iconographie de l'art chrétien, III, vol. 3, Paris, 1959, p. 1269

${ }^{6}$ VORÁGINE, Santiago de la: La Leyenda Dorada, traduc. De Fray José Manuel Macías, Madrid, 1982, p. 47

${ }^{7}$ Ibídem

${ }^{8}$ DÍAZ PADRÓN, Matías: La pintura flamenca del siglo XVII en España, Ms. Universidad Complutense, Madrid, 1975, tomo IV, fol. 1344; ídem "Frans Francken II en la Catedral de Sevilla. Algunas consideraciones a su obra en España”, Revista Goya, 1975, n 129, p. 168; Ursula Härting, Frans Francken der Jüngere (1581-1642). Die Gemälde mit Kritischem Oeuvrekatalog, Freren, 1989, pp. 408, 410, 411. (Madrid, Sevilla, Toledo y España). 
Es un deleite para los ojos la elegancia y la gracia narrativa de los personajes. Algunos modelos, como el rostro del apóstol de largas barbas lo repite en la Adoración de los Magos del museo de Bellas Artes de Soissons, en la Santa Cena de colección privada de Bruselas y en La creación de Adán y Eva de Götemborg.

En el fondo de la estancia y sobre una repisa está un cuadro dentro del cuadro: típico de la pintura de gabinete. Reconocemos la adoración de la serpiente de metal que Francken debió tomar de pinturas de Rubens o de Van Dyck. Esta dramática escena reúne a los israelitas ávidos de la tierra prometida. Parece evocar la duda de santo Tomás: "hizo pues Moisés una serpiente de bronce y la puso por señal a la cual mirándola los mortales sanaban" (Números 21, 9). La vara con la serpiente en el centro alza la mirada del espectador a las alturas (Figura 5).

La tabla renuncia a los ricos accesorios que acostumbra a añadir Frans Francken en historias similares. No es fácil fijar una fecha con precisión, pero quizá podemos aventurar que se trata de una obra de su última producción con visión de gran formato.

No conocemos que Frans Francken II haya tratado este asunto en otra ocasión, tanto en obras existentes como en las documentadas, cuando fue muy frecuente el abuso repetitivo de los asuntos. Hoy podemos invitar a incorporar esta pintura excepcional en el corpus de Ursula Härting. Una pintura erróneamente atribuida a Frans Francken I.

Frans Francken II afirma la originalidad de esta pintura con la ostensible expresión "IN Fec." (inventó e hizo). Igual que precisó en otras con la " $A$ " delante de la fecha. Es aviso del año de la ejecución con igual caligrafía. Observamos en la distancia del lado izquierdo del pilar una ligera pérdida de color con la numeración borrada (figura 6). Lo que no impide Podemos aventurar una fecha después del año 1628. La caligrafía es similar a las de El rey Midas del museo de Brusnwick y El Hijo pródigo del museo de Carlsruhe.

Fecha de recepción: 20 de septiembre de 2014

Fecha de aceptación: 28 de noviembre de 2014 


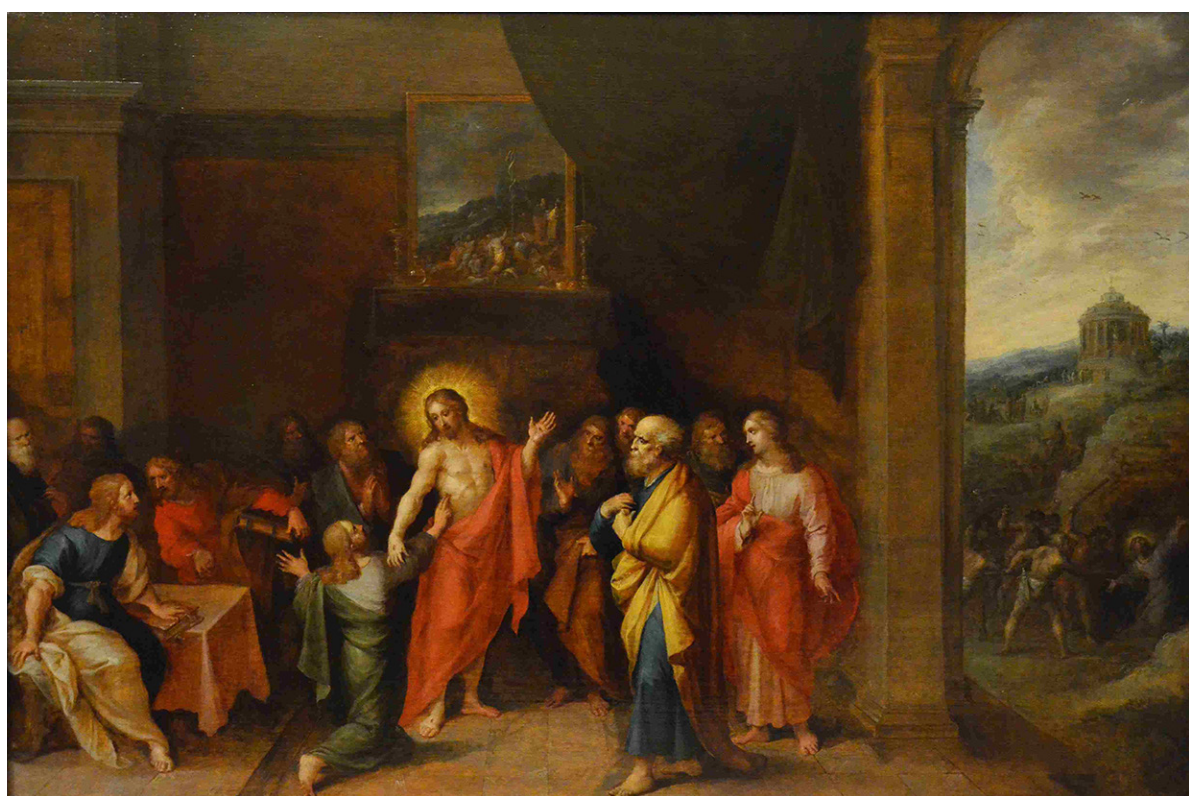

Figura 1. Frans Francken II, La incredulidad de Santo Tomás, colección privada.

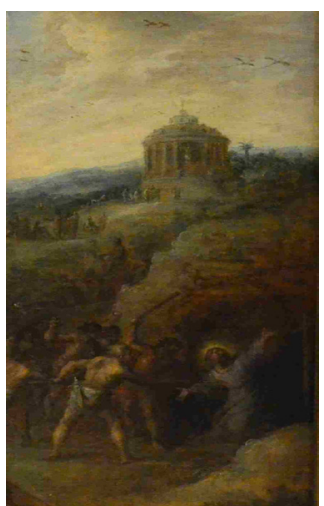

Figura 2. Frans Francken II, La incredulidad de Santo Tomás, colección privada (detalle con el martirio de Santo Tomás).

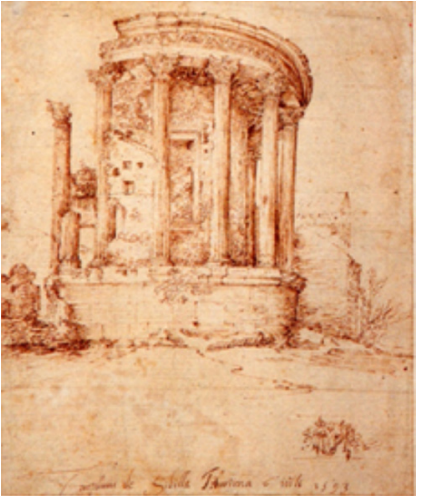

Figura 3. Jan Brueghel el Viejo, dibujo del templo de la Sibila de Tívoli en Roma (1593), Fundación Custodia, Paris.

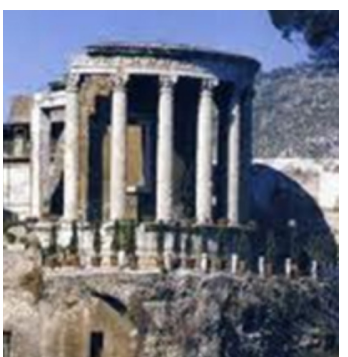

Figura 4. Templo de la Sibila de Tívoli en Roma. 


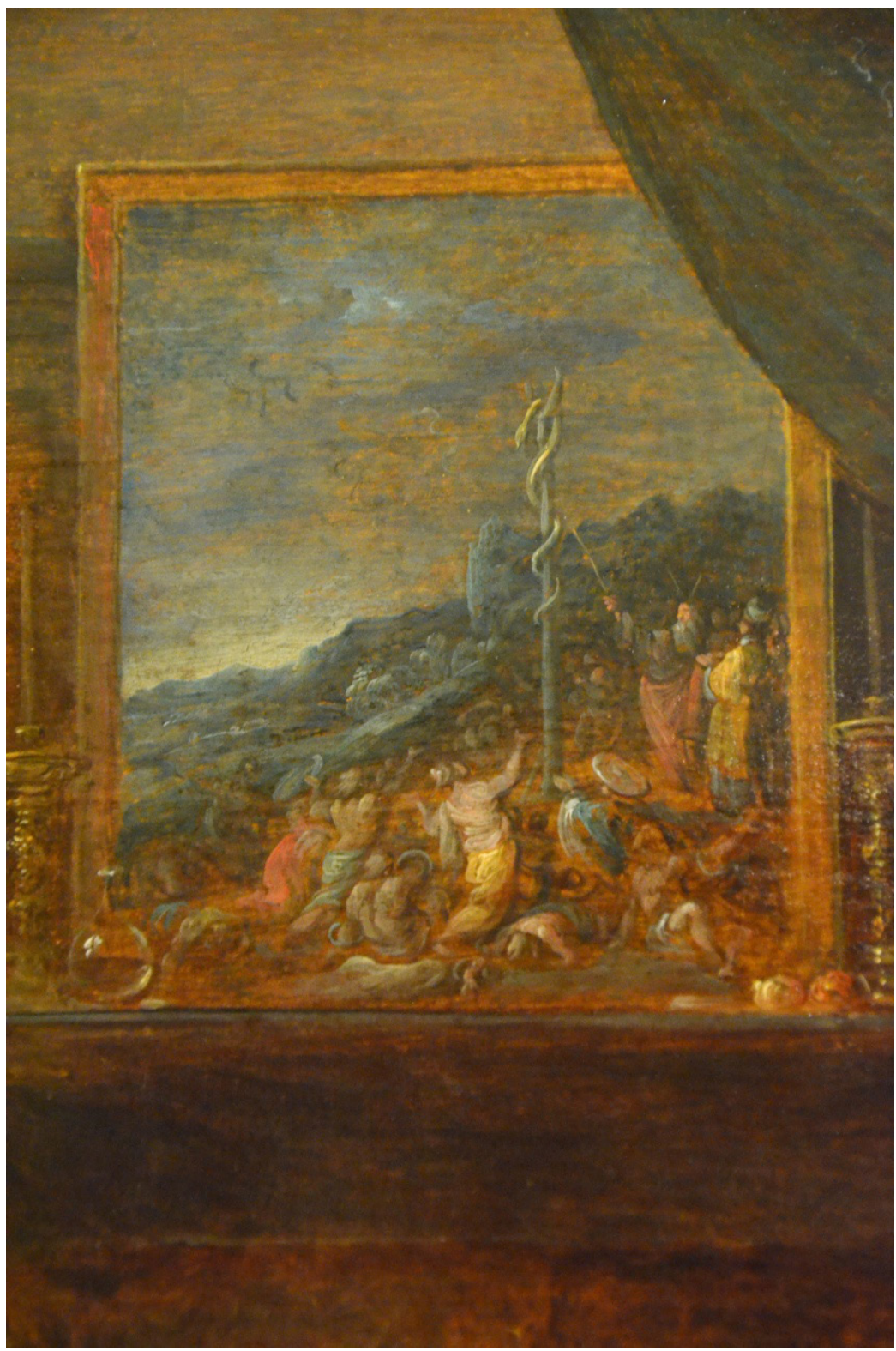

Figura 5. Frans Francken II, La incredulidad de santo Tomás, (detalle con la serpiente de metal). 


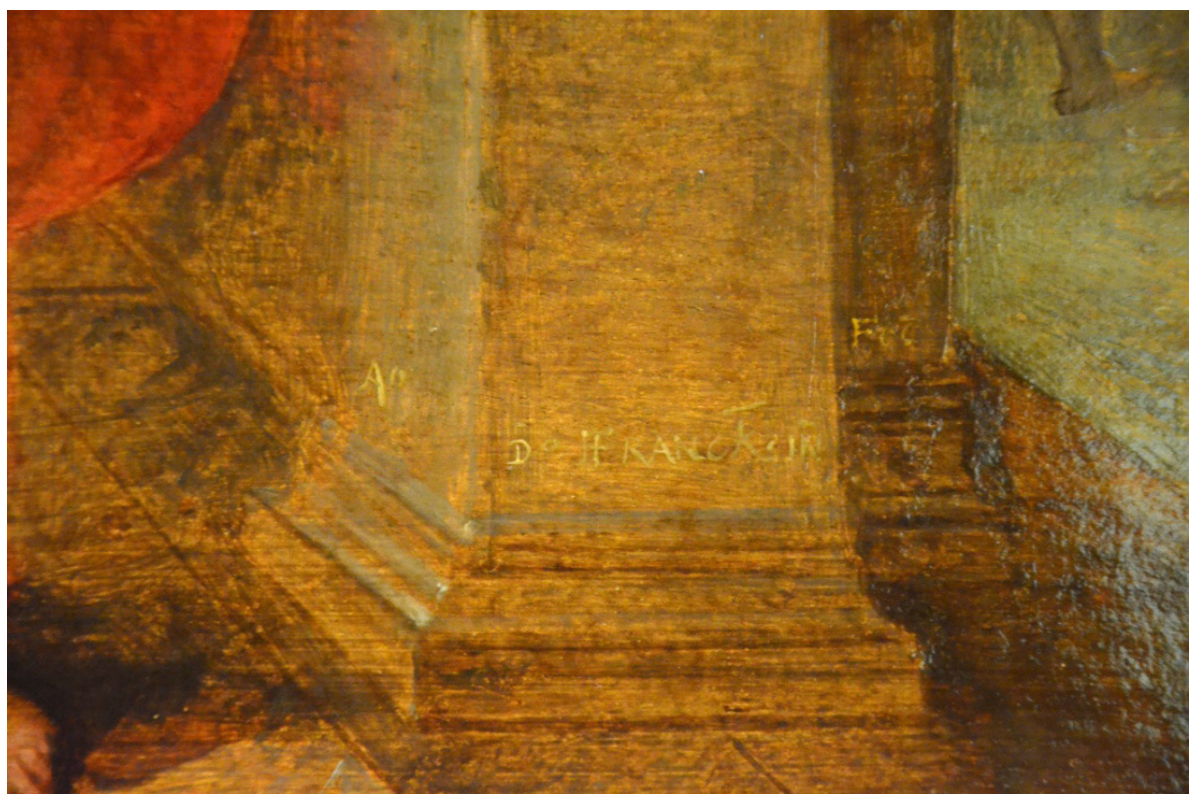

Figura 6. Frans Francken II, La incredulidad de santo Tomás (detalle de la firma). 